Quality : Jurnal Kesehatan

Volume 15, Nomor 2 Tahun 2021

pISSN : 1978-4325, eISSN : 2655-2434, DOI: 10.36082/qjk.v15i2.194

\title{
WAKTU KONTAK PETUGAS DENGAN PASIEN TERHADAP KUALITAS LAYANAN: STUDI PERSPEKTIF PETUGAS KESEHATAN DI PUSKESMAS $\mathrm{X}$
}

Merita Arini' ${ }^{1}$,

${ }^{1}$ Departemen Ilmu Kesehatan Keluarga dan Kesehatan Masyarakat, Program Studi Sarjana Kedokteran, Fakultas Kedokteran dan Ilmu Kesehatan, Universitas Muhammadiyah Yogyakarta, Indonesia

Info Artikel Abstrak

Genesis Naskah:

Submitted: 13-02-2021

Revised: 10-10-2021

Accepted: 15-11-2021
Interaksi dan durasi waktu kontak pasien dan petugas kesehatan di fasilitas kesehatan primer dengan sumber daya terbatas masih menjadi isu penting dalam upaya pemberian layanan kesehatan yang berkualitas dan aman. Tujuan penelitian ini adalah untuk mengkaji gambaran waktu kontak dan proses layanan serta mengeksplorasi persepsi petugas kesehatan terkait kualitas layanan kesehatan Puskesmas. Penelitian ini merupakan sebuah studi kasus berupa mixed method dengan desain sequential explanatory. Data kuantitatif digali secara deskriptif dengan melakukan observasi untuk mengukur waktu kontak dalam 1 hari kerja terhadap pasien rawat jalan secara konsekutif $(n=70)$ dan dilanjutkan dengan wawancara mendalam untuk menggali persepsi petugas terhadap waktu dan proses pelayanan. Informan terdiri dari 2 dokter dan 2 perawat di sebuah Puskesmas di Kabupaten Gunungkidul, Daerah Istimewa Yogyakarta. Hasil penelitian menunjukkan rata-rata total waktu yang dihabiskan setiap pasien dengan dokter adalah 304,4 detik, dan perawat 152,5 detik. Terdapat tiga tema yang meliputi keterbatasan waktu, budaya keselamatan, dan persepsi pasien terhadap kualitas. Keterbatasan waktu terkait dengan kurangnya jumlah petugas dan beban admisnistratif. Budaya keselamatan yang takterpisahkan dari kualitas layanan mencakup aspek keterbukaan komunikasi dan akreditasi. Persepsi pasien terhadap kualitas layanan mencakup harapan singkatnya waktu tunggu dan terpenuhinya preferensi mereka. Didapatkan kesimpulan bahwa masalah keterbatasan sumber daya manusia masih tinggi dan menjadi kendala di fasilitas kesehatan primer di Indonesia. Penting untuk memastikan beban dan alur kerja petugas sesuai di samping upayaupaya peningkatan mutu yang telah dilakukan di layanan primer.

\section{HEALTH WORKERS' CONTACTS TIME WITH PATIENTS AGAINST QUALITY OF SERVICE: A PERSPECTIVE STUDY ON HEALTH OFFICERS AT X COMMUNITY HEALTH CENTER}

\begin{tabular}{ll}
\hline Keywords: & Abstract \\
\cline { 2 - 2 } $\begin{array}{l}\text { time-motion study, primary } \\
\text { care, quality healthcare, }\end{array}$ & The interaction and duration of contact time between patients and health workers in primary health \\
health workers contact time & facilities with limited resources are still crucial issues in providing quality and safe health services. \\
& $\begin{array}{l}\text { This study aimed to explore healthcare workers' contact time and service processes, and health } \\
\text { workers' perceptions regarding quality in a community health center. This was a case study through } \\
\text { mixed method with a sequential explanatory design. Quantitative data were investigated } \\
\text { descriptively by observation to measure contact time in } 1 \text { working day for outpatients }(n=70 \\
\text { patients) in one working day consecutively and followed by in-depth interviews (qualitative) to }\end{array}$ \\
\hline
\end{tabular}

(C) Poltekkes Kemenkes Jakarta I ISSN 2655-2434

Jl. Wijaya Kusuma No. 47-48 Cilandak Jakarta Selatan, Indonesia email: jurnalquality@poltekkesjakarta1.ac.id

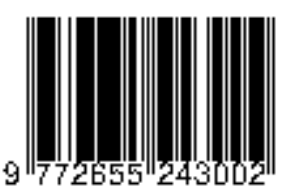


explore the officers' perceptions of the time and service process. The informants consisted of 2 doctors and two nurses who provided services at community healthcare in Gunungkidul Regency, Yogyakarta Special Region. The results showed that each patient's average total contact time with doctors was 304.4 seconds, and nurses were 152.5. There were three themes obtained, including time constrain, safety culture, and patient perceptions of quality. Time constraints are related to the lack of staff and their administrative burden. Safety culture which is inseparable from service quality includes aspects of communication openness and accreditation. Patients' perceptions of service quality include expectations of short waiting times and their preference. It was concluded that human resource problems with high patient and administrative burdens are common obstacles in Indonesia's primary health facilities. It is essential to ensure that HCWs' workload and workflow are appropriate besides the quality improvement efforts in primary care.

\author{
Korespondensi Penulis: \\ Merita Arini \\ Kampus Terpadu UMY, Universitas Muhammadiyah Yogyakarta, Tamantirto, Kasihan, Bantul, DIY, Indonesia
}

Email:merita.arini@umy.ac.id 


\section{Pendahuluan}

Kualitas dan keamanan dalam fasilitas kesehatan merupakan global concern sejak dicanangkan dalam "To Err is Human" oleh The Institute of Medicine (IOM) pada tahun 1999. Kualitas pelayanan kesehatan mencakup penyediaan perawatan yang efektif dan aman (safe), tercermin dalam budaya keunggulan (culture of excellence), serta menghasilkan luaran yang optimal atau diinginkan (Allen-Duck et al., 2017). Dari aspek keselamatan pasien, sebanyak 48.000 sampai dengan 98.000 kematian per-tahun terjadi akibat medical error, lebih tinggi dari data kematian akibat kecelakaan pesawat maupun kecelakaan kendaraan lainnya. (Institute of Medicine, 2000). Berdasarkan laporan IOM tersebut dinyatakan bahwa mayoritas insiden-insiden tersebut sebenarnya dapat dicegah/ preventable. Keselamatan pasien merupakan salah satu faktor terpenting dalam peningkatan mutu serta menjadi aspek fundamental pelayanan kesehatan di seluruh dunia. Hal tersebut menuntut terpenuhinya berbagai dimensi kualitas yang meliputi akses, ketepatan waktu, efikasi, efisiensi, kesesuaian, serta acceptability dalam pelayanan kesehatan (Marchon et al., 2015; Flott et al., 2019).

Studi terhadap kualitas layanan dan keselamatan pasien di fasilitas kesehatan tingkat pertama (FKTP) hingga saat ini masih tertinggal dibandingkan setting rumah sakit (RS) (Sheikh et al., 2013; Giles et al., 2015). Ketertinggalan tersebut dapat dilihat dari jumlah publikasi maupun inovasiinovasi untuk meningkatkannya tidak sebanyak yang dilakukan di RS. Di sisi lain, diketahui bahwa FKTP merupakan kontak pertama layanan kesehatan yang pada umumnya lebih banyak digunakan masyarakat, termasuk di Indonesia (Marchon dan Junior, 2014; Mahendradhata et al., 2017). Kualitas dan keselamatan pasien di layanan primer menjadi emerging global priority yang harus ditingkatkan sebagaimana dicanangkan World Health Organization (WHO, 2008).

Layanan primer, termasuk Puskesmas (Pusat Kesehatan Masyarakat) di Indonesia secara umum memiliki karakteristik unik dalam hal pelayanan kesehatan dan implementasi keselamatan pasien di dalamnya. Secara global, hal ini terkait dengan kondisi FKTP yang umumnya masilh terkendala dengan masalah akses, keterbatasan infrastruktur, sumber daya manusia, teknologi, dan

(C) Poltekkes Kemenkes Jakarta I

Jl. Wijaya Kusuma No. 47-48 Cilandak Jakarta Selatan, Indonesia email: jurnalquality@poltekkesjakarta1.ac.id logistik seperti obat-obatan (Australian Commission on Safety and Quality in Healthcare, 2011). Berbagai faktor internal dan eksternal seperti kebijakan dan sistem pembiayaan kesehatan turut berperan mempengaruhi penyelenggaraan layanan yang berkualitas dan aman di FKTP (Smith et al., 2017; Singh et al., 2017).

Tenaga kesehatan di negara berkembang seringkali dihadapkan pada beban kerja yang tinggi dan terbatasnya waktu kontak dengan pasien (Konrad et al., 2010). Waktu kontak yang cukup diharapkan dapat memenuhi kebutuhan pasien untuk anamnesis, pemeriksaan fisik, penegakkan diagnosis, bahkan berbagai upaya self-management support yang dibutuhkan pasien (Agrimon, 2014). Memahami waktu yang dibutuhkan dan kompleksitas alur kerja klinis dapat membantu menilai beberapa masalah kualitas layanan paling kritis, termasuk keselamatan pasien dengan mendeteksi kesalahan, meningkatkan mutu layanan dengan mengevaluasi ketepatan waktu, dan prosedur, produktivitas, efisiensi, dan mengoptimalkan beban kerja dan alokasi waktu petugas (Lopetegui et al., 2014). Oleh karena itu, tujuan dari penelitian ini adalah untuk mendapatkan gambaran waktu kontak petugas kesehatan dan pasien, serta perspektif petugas terhadap kualitas layanan terkait waktu kontak di FKTP (Puskesmas).

\section{Metode}

Penelitian dilakukan di Puskesmas di area pedesaan di Kabupaten Gunungkidul, Daerah Istimewa Yogyakarta (DIY). Pengambilan data dilakukan pada satu hari kerja yang ditetapkan secara convenient.

Penelitian ini merupakan preliminary study tentang kualitas dan keselamatan pasien di layanan primer. Penelitian ini merupakan studi kasus yang dilakukan menggunakan desain mixed method dalam 2 tahap sequential explanatory. Tahap pertama dilakukan observasi tehadap patient motion time saat mendapatkan pelayanan sejak anamnesis dan atau pemeriksaan fisik, penegakkan diagnosis, dan edukasi oleh dokter dan atau perawat di unit rawat jalan/ruang pemeriksaan umum. Peneliti bertindak sebagai observer eksternal/non-partisipatif dan melakukan observasi selama 1 hari terhadap seluruh

ISSN 2655-2434 
pasien secara konsekutif, Didapatkan 70 pasien yang dapat diikuti dari 109 pasien yang terdaftar. Observasi ditujukan untuk mendapatkan gambaran rata-rata waktu yang dibutuhkan oleh petugas kesehatan dalam berinteraksi dengan pasien. Tahap berikutnya dilakukan wawancara mendalam terhadap 2 orang dokter dan 2 orang perawat yang bertugas. Instrumen yang digunakan dalam penelitian ini adalah stopwatch, field notes, dan panduan wawancara mendalam. Pertanyaan dalam wawancara mendalam meliputi pertanyaan tentang pengalaman memberikan layanan dengan durasi waktu yang ada, hambatan, serta faktor pemungkin perbaikan.

Beberapa upaya dilakukan untuk menjaga kualitas data dan hasil analisis. Validitas data kuantitatif dijaga dengan melakukan double entry \& check. Adapun keabsahan data/ trustworthiness dilakukan dengan melakukan triangulasi sumber, member check, dan audit rail. Peneliti merupakan wanita dengan latar belakang pendidikan kedokteran dan magister manajemen rumah sakit, memiliki riwayat melakukan penelitian kualitatif dan mempublikasikannya. Selain itu, peneliti memiliki raport yang dekat dengan para informan, sehingga memungkinkan data yang didapatkan sesuai dengan kondisi pelayanan sehari-hari. Transferability penelitian ini digambarkan dengan adanya thick description mengenai setting penelitian.

Data kuantitatif dianalisis secara deskriptif untuk mendapatkan rata-rata, median, serta standar deviasi waktu kontak. Terhadap data hasil wawancara dilakukan analisis tematik dengan melakukan reduksi data dan koding hingga didapatkan tema-tema yang menggambarkan hasil penelitian.

Penelitian yang dilakukan sebelum pandemi COVID-19 ini dilakukan setelah mendapatkan perijinan dari pimpinan Puskesmas. Informan telah mendapatkan penjelasan dan memberikan persetujuan mengikuti penelitian.

\section{Hasil}

Fasilitas kesehatan primer yang diteliti merupakan jenis Puskesmas daerah pedesaan dan merupakan satu-satunya FKTP di salah satu

(C) Poltekkes Kemenkes Jakarta I

J1. Wijaya Kusuma No. 47-48 Cilandak Jakarta Selatan, Indonesia email: jurnalquality@poltekkesjakarta1.ac.id kecamatan di Kabupaten Gunungkidul, DIY. Kecamatan tersebut memiliki berpenduduk 38.749 jiwa yang tersebar di 7 desa/ kelurahan. Puskesmas ini juga dibantu dengan 6 Puskesmas pembantu (Pustu) yang tersebar di masing-masing desa. Puskesmas induk dilayani oleh 2 dokter dan 2 perawat yang bertugas di ruang pemeriksaan umum dan 2 orang berjaga di IGD di samping petugas kesehatan lainnya. Hanya terapat 1 orang perawat atau bidan yang bertugas di Pustu (tanpa dokter). Saat penelitian ini dilakukan, Puskesmas ini berada dalam tahap persiapan akreditasi.

Hasil dari tahap pertama penelitian ini adalah didapatkan rata-rata waktu kontak antara petugas kesehatan dengan pasien di Puskesmas Induk pada ruang pemeriksaan umum. Terdapat 29 pasien yang diperiksa dokter dan diobservasi, serta 41 pasien yang diperiksa perawat dan diobservasi. Rata-rata waktu kontak dengan dokter sejak pasien masuk hingga keluar dari ruang pemeriksaan yaitu 304,4 detik pada hari dilakukan observasi. Waktu kontak dengan perawat memiliki rata-rata yang lebih rendah, yaitu 152,5 detik. Hal ini dapat dilihat dalam tabel 1 sebagai berikut.

Tabel 1. Waktu Kontak Pasien-Petugas (dalam detik)

\begin{tabular}{lll}
\hline Kriteria & $\begin{array}{l}\text { Dokter } \\
(\mathrm{n}=29)\end{array}$ & $\begin{array}{l}\text { Perawat } \\
(\mathrm{n}=41)\end{array}$ \\
\hline Mean & 304,41 & 152,51 \\
Standar deviasi & 150,84 & 115,08 \\
Median & 269 & 124 \\
Minimum & 84 & 43 \\
Maksimum & 690 & 782 \\
\hline
\end{tabular}

Selama observasi didapatkan adanya beberapa masalah keselamatan pasien. Terdapat 2 near-miss incident (Kejadian Nyaris Cidera/KNC) terkait kesalahan identifikasi pasien serta terdapat illegible writing baik pada rekam medis dan resep yang merupakan KPC (Kejadian Potensial Cidera). Near-miss yang didapatkan terjadi akibat alur proses serta eksekusi pekerjaan yang terkesan terburu-buru. Adapun illegible writing dilakukan oleh petugas senior yang menangani pasien.

Dalam observasi diperoleh fakta bahwa tidak semua pasien diperiksa oleh dokter. Hanya kasusISSN 2655-2434

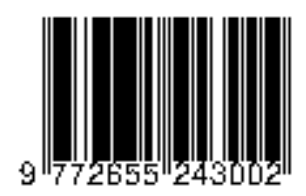


kasus yang dianggap lebih sulit yang diserahkan kepada dokter. Kasus yang membutuhkan surat pengantar rujukan juga diserahkan kepada dokter meskipun tidak membutuhkan pemeriksaan lanjutan. Pasien yang harus mendapat surat pengantar, dibuatkan oleh dokter dalam sistem informasi P-Care untuk rujukan sesuai aturan yang ditetapkan oleh asuransi kesehatan nasional/ BPJS Kesehatan (Badan Penyelenggara Jaminan Sosial Kesehatan).

Berdasarkan wawancara mendalam didapatkan tema dan kategori yang ditampilkan dalam skema pada Gambar 1 berikut ini.

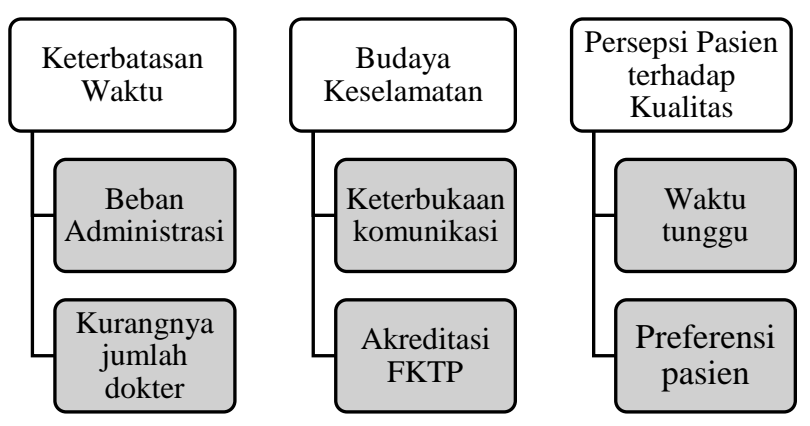

Gambar 1. Skema Tema Persepsi Petugas tentang Waktu Kontak Petugas-Pasien dan Kualitas Layanan Kesehatan

\section{Tema 1: Keterbatasan Waktu}

Terdapat dua kategori dalam tema pertama, yaitu beban adminsitrasi dan kurangnya jumlah dokter. Dalam pengamatan peneliti, dokter yang mengerjakan surat rujukan menghabiskan sebagian besar waktu untuk kewajiban administratif. Dokter tidak melakukan pemeriksaan fisik kepada seluruh pasien selama periode observasi, selebihnya terhadap pasien hanya dilakukan history taking. Hal ini diakui dokter karena terburu waktu sesuai pernyataan:

"Iya begini ini, semua harus dikerjakan dengan cepat supaya ngga diprotes pasien yang menunggu" (dokter, wanita, 37 tahun, $\mathrm{R} 1)$

Perawat melakukan pekerjaan sebagaimana yang dikerjakan dokter mulai dari anamnesis hingga

(C) Poltekkes Kemenkes Jakarta I

Jl. Wijaya Kusuma No. 47-48 Cilandak Jakarta Selatan, Indonesia email: jurnalquality@poltekkesjakarta1.ac.id pemeriksaan fisik sederhana seperti tanda vital, mengisi rekam medis (asuhan keperawatan), dan menetapkan terapi. Kadangkala perawat melakukan hal yang bukan menjadi tugasnya oleh karena keterbatasan tugad dokter. Dengan kondisi yang ada, petugas yang diwawancarai mengidentifikasi bahwa kurangnya jumlah dokter yang ditempatkan di Puskesmas menyebabkan sebagian besar pelayanan harus didelegasikan kepada petugas lain. Perawat mengerjakan terapi medis sesuai pendelegasian wewenang dari dokter sesuai ketetapan standar akreditasi. Hal ini seperti yang dinyatakan dokter:

"Perawat memang tidak boleh memberikan terapi medis, tapi karena keterbatasan tenaga maka terpaksa harus dilakukan terutama di Pustu (Puskesmas Pembantu) yang memang tidak ada dokter yang bertugas. Kalau di Puskesmas induk juga sama, tidak mungkin semua pasien ditangani dokter." (dokter, lakilaki, 32 tahun, R2)

"Seharusnya... semua pendelegasian tugas tertulis, tapi memang belum semua tercantum dalam SK. Baru secara umum saja." (dokter, laki-laki, 32 tahun, R2)

Baik dokter dan perawat merasa memiliki keterbatasan waktu dalam berinteraksi dengan pasien. Petugas menyadari amat pentingnya waktu yang cukup untuk melayani pasien agar tidak terjadi kesalahan.

"... kami kekurangan waktu, semua serba harus cepat-cepat, kayaknya jadi kurang berkualitas. Khawatir juga sebenernya kalau ada kesalahan KTD tapi ya mau bagaimana lagi kalau harus melayani 100 pasien dari jam 8 sampai selesai, belum lagi kalau mau ngerjain data." (Perawat, Wanita, 38 tahun, R3)

\section{Tema 2: Budaya Keselamatan}

Tema ini meliputi dua kategori yaitu keterbukaan komunikasi dan akreditasi FKTP (Fasilitas Kesehatan Tingkat Pertama). Saat penelitian ini berlangsung, Puskesmas sedang menjalani proses persiapan akreditasi nasional. Dengan adanya proses ini, petugas menyatakan lebih mudah untuk mengajak kolega lain bekerjasama dalam memperbaiki pelayanan. Sebelum akreditasi ISSN 2655-2434

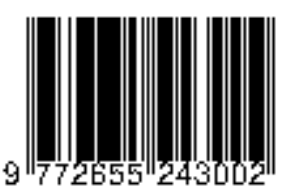


mulai dipersiapkan, budaya keterbukaan komunikasi di Puskesmas sudah berjalan cukup baik. Budaya suku Jawa yang kekeluargaan dan kegotongroyongan dinyatakan turut membentuk suasana kerja yang nyaman. Hal tersebut seperti yang tertuang dalam kutipan wawancara berikut ini.

"Kami biasa kok konsul sama dokter R. Ada apa-apa kami bilang. Kalau ada yang sulit kami tanya." (Perawat, wanita, 38 tahun, R3)

"Selama persiapan akreditasi ini memang jadi lebih mudah ngoyak-oyak teman-teman yang lain. Setidaknya kalau ada hal-hal yang perlu diperbaiki bisa kita sampaikan. Jadi akreditasi itu memudahkan." (Perawat, wanita, 52 tahun, R4)

"Suasana kerja di Puskesmas ini sebenarnya nyaman, orang-orangnya enakan. Biasanya kalau ada apa-apa dan ngga berani ngomong saat rapat, pada ngomongnya ke saya (tertawa), lalu saya bantu menyampaikan. Mereka itu punya dedikasi yang tinggi meskipun tugasnya berat." (dokter, laki-laki, 32 tahun, R2)

\section{Tema 3: Persepsi Pasien terhadap Kualitas}

Tema ketiga merupakan kesan petugas terhadap sikap pasien selama pelayanan. Terkait dengan waktu layanan, petugas menyatakan bahwa masyarakat masih menganggap makin cepat layananan berarti makin berkualitas. Selain itu, pasien umumnya menganggap pelayanan dokter lebih baik dan meminta konsultasi secara khusus kepada dokter. Pasien juga umumnya lebih menyukai layanan dapat selesai sekaligus dalam satu tempat (tidak dirujuk). Hal-hal tersebut sebagaimana kutipan informan sebagai berikut.

"Pasien itu maunya cepet-cepet. Kalau nunggu lama di luar mereka pada protes." (dokter, wanita, 37 tahun, R1)

"Pasien kadang milih, maunya sama dokter. Tapi ya gimana lagi, tetap harus dibagi-bagi tenaganya. Kalau kasusnya berat kami pasti konsul ke dokter." (Perawat, Wanita, 38 tahun, R3)

(C) Poltekkes Kemenkes Jakarta I

Jl. Wijaya Kusuma No. 47-48 Cilandak Jakarta Selatan, Indonesia email: jurnalquality@poltekkesjakarta1.ac.id
"Pasien seringkali sudah disarankan rujuk, tapi banyak yang tetap minta ditangani di Puskesmas saja. Kami tidak bisa memaksakan pilihan, cuma bisa edukasi dan menjelaskan apa saja yang harus dilakukan kalau tetap maunya berobat di Puskesmas." (Dokter, lakilaki, 32 tahun, R2)

\section{Pembahasan}

Penelitian yang dilakukan merupakan studi awal tentang kualitas layanan di FKTP area rural di Indonesia. Hasil penelitian ini menggambarkan tentang terbatasnya waktu kontak pasien dengan petugas di layanan primer yang berdampak pada adanya risiko tidak terpenuhinya kualitas layanan kesehatan dan keselamatan pasien. Meskipun demikian, baik dokter maupun perawat pada penelitian di atas sudah memiliki persepsi yang baik tentang pentingnya menjaga mutu dan keselamatan pasien dalam memberikan pelayanan kesehatan.

a. Keterbatasan Waktu

Hasil penelitian ini menunjukkan singkatnya waktu efektif kontak dokter dan perawat dengan pasien di layanan rawat jalan Puskesmas. Tidak jauh berbeda dengan hasil dalam penelitian ini, waktu kontak pasien dewasa di rural area di Malawi ratarata mencapai 2,3 menit dan 1,7 menit untuk pasien anak (Jafry et al., 2016). Di negara-negara berpendapatan rendah dan berkembang lainnya juga banyak didapatkan rata-rata waktu konsultasi masih berada di bawah satu menit (Irving et al., 2017).

Kondisi pelayanan kesehatan di Indonesia sebagaimana hasil penelitian ini menggambarkan adanya keterbatasan sumberdaya. Dalam hal sumber daya manusia (SDM), para petugas kesehatan memiliki beban kerja tinggi terkait jumlah pasien, administrasi, serta program kesehatan lainnya di Puskesmas. Meskipun rasio petugas kesehatan terhadap populasi di Indonesia terus meningkat dalam dua dekade terakhir, namun tetap masih berada di bawah standar yang ditetapkan WHO (Mahendradhata et al., 2017). Jumlah penduduk padat dan belanja kesehatan per-kapita rendah berhubungan dengan rendahnya waktu kontak petugas dan pasien yang lebih singkat (Irving et al., 2017).

Sebagaimana didapatkan dalam penelitian ini, pada praktik layanan kesehatan, petugas ISSN 2655-2434 
kesehatan menghadapi tuntutan pekerjaan yang menyita banyak waktu mereka. Meningkatnya prosedur administrasi untuk layanan perawatan kesehatan (misalnya persyaratan layanan dan otorisasi, proses tinjauan utilisasi, dan lain sebagainya) mengalihkan banyak waktu berkualitas yang seyogyanya digunakan untuk berinteraksi dengan pasien sebagaimana dilaporkan juga dalam penelitian di Peru (Leslie et al., 2021). Para dokter cenderung menjadi kurang menggali pertanyaan tentang gejala utama pasien, kurang detail dalam memeriksa pasien, dan tidak memberikan nasihat yang adekuat kepada pasien karena keterbatasan waktu (Tsiga et al., 2013). Selain itu, keterbatasan waktu konsultasi menimbulkan dampak meningkatnya beban dan stress petugas serta kurang optimalnya luaran pasien (Irving et al., 2017).

Meskipun waktu konsultasi atau waktu kontak merupakan data yang dapat diukur atau bersifat kuantitatif, namun demikian terdapat variabel lain yang menentukan kecukupannya. Di negara maju dan populasi urban seperti Jerman, para dokter tetap memiliki persepsi bahwa waktu yang dibutuhkan kurang dalam memberikan berbagai layanan kesehatan yang dibutuhkan pasien (Von Dem Kesebeck et al., 2019). Meskipun di negara-negara maju seperti Amerika Serikat, Inggris, dan Australia waktu konsultasi terus mengalami peningkatan durasi, namun kecukupan waktu layanan yang berkualitas lebih dibutuhkan dari sekedar lamanya interaksi (Irving et al., 2017). Oleh karena itu, upaya peningkatan mutu tidak cukup hanya dengan meningkatkan durasi waktu kontak, namun kualitas layanan kesehatan itu sendiri.

Penelitian ini mendapatkan adanya KNC dan KPC yang terkait dengan keterbatasan waktu layanan. Hambatan waktu layanan tersebut menyebabkan petugas terburu-terburu dalam melakukan pekerjaannya, sebagaimana dalam penelitian ini terjadi KNC kekeliruan identitas pasien yang masih dapat diatasi sebelum terjadi insiden, serta KPC akibat tulisan dokter yang sulit terbaca. Dalam berbagai penelitian, terbatasnya waktu berpengaruh terhadap pemenuhan panduan pelayanan yang seharusnya dilakukan. Semakin tinggi beban kerja dan singkatnya waktu layanan berhubungan dengan

(C) Poltekkes Kemenkes Jakarta I

Jl. Wijaya Kusuma No. 47-48 Cilandak Jakarta Selatan, Indonesia email: jurnalquality@poltekkesjakarta1.ac.id keamanan, dan kualitas layanan secara umum. Hal ini ditunjukkan dengan rendahnya perhatian langsung petugas kepada pasien, rendahnya kepatuhan melengkapi rekam medis, gangguan proses layanan, penurunan sikap keselamatan (safety attitude), serta peningkatan risiko infeksi (PérezFrancisco et al., 2020)

\section{b. Budaya Keselamatan Pasien}

Dalam penelitian ini, budaya keselamatan yang mulai terbangun karena persiapan proses akreditasi. Tahap ini bermanfaat sebagai pendorong dan faktor pemungkin upaya perbaikan. Beberapa studi tentang peran akreditasi dalam peningkatan mutu di primary care menunjukkan hasil yang bervariasi namun potensial bermanfaat bagi peningkatan mutu (Haj-ali, 2012; Sterling et al., 2012; O'Beirne, et al., 2013; El-Jardali et al., 2014; Diab, 2015). Untuk menjawab kebutuhan layanan masyarakat dengan lebih baik, akreditasi merupakan langkah awal yang penting untuk membangun sistem dalam peningkatan safety culture dan kualitas sistem layanan kesehatan seperti Puskesmas (ElJardali et al., 2014).

Pada Puskesmas yang diteliti, keterbukaan komunikasi merupakan faktor pemungkin untuk mewujudkan penyelenggaraan layanan kesehatan yang berkualitas. Keterbukaan komunikasi merupakan salah satu dimensi vital dalam budaya keselamatan yang penting untuk mendukung pembelajaran dan upaya perbaikan mutu berkesinambungan (Halligan dan Zecevic, 2011; Agency for Healthcare Research and Quality's (AHRQ), 2016). Di berbagai negara, penggunaan instrumen-instrumen, sistem, dan pelatihanpelatihan untuk meningkatkan komunikasi efektif antar petugas juga merupakan strategi kunci dalam meningkatkan budaya keselamatan pasien (Martinez et al., 2016).

\section{c. Persepsi Pasien terhadap Kualitas}

Pada hasil penelitian di Gunungkidul ini, sebagian pasien dalam penelitian tersebut masih beranggapan bahwa pelayanan yang berkualitas adalah yang cepat ditangani atau pendek waktu tunggunya. Persepsi mengenai mutu bagi bagi pemberi dan penerima layanan seringkali berbeda. Meskipun di negara-negara berpendapatan rendah

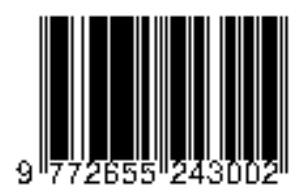


memiliki rata-rata waktu konsultasi singkat, umumnya pasien memiliki persepsi yang berbeda (Irving et al., 2017). Pada penelitian tersebut didapatkan bahwa lamanya waktu kontak tidak berhubungan dengan persepsi pasien terhadap kualitas pelayanan.

Preferensi pasien dalam penelitian ini ditunjukkan dengan memilih petugas kesehatan yang melayaninya. Dalam konsep patient centered care (PCC), layanan kesehatan harus menghormati preferensi pasien, nilai-nilai yang dianut, dan memberikan layanan sesuai kebutuhan mereka (Newell dan Jordan, 2015). Pada penelitian di Belanda, pasien secara umum memilih dokter yang menerapkan konsep PCC terutama yang dapat berkomunikasi dengan baik tanpa memperhatikan latar belakang lainnya (Paternotte et al., 2017). Di sisi lain, pasien umum memilih dokter karena alasan profesionalitas dan reputasi (Petrilli et al., 2015; Mun et al., 2019).

Preferensi pasien yang mengemuka dalam penelitian ini meliputi one stop services atau selesainya layanan kesehatan dalam satu fasilitas kesehatan saja. Dalam paradigma layanan kesehatan modern, harapan mengenai pelayanan terintegrasi yang tidak rumit, cepat, dan dilakukan dalam satu atap, sangat penting untuk mencegah bertambahnya beban pasien karena harus mengakses layanan kesehatan yang terfragmentasi (Leppin et al., 2015). Memenuhi preferensi pasien dalam hal ini dapat meningkatkan akses mereka kepada layanan kesehatan termasuk kepatuhannya dalam menjalankan pengobatan untuk mendapatkan outcome pengobatan yang lebih baik (Wong et al., 2013) . Namun demikian, karena terbatasnya sumber daya di FKTP seperti Puskesmas, layanan pasien terintegrasi tersebut masih membutuhkan banyak upaya perbaikan.

Secara umum, penelitian ini dapat memberikan gambaran kondisi keterbatasan layanan kesehatan primer di rural area terkait dengan durasi kontak pasien-petugas. Eksplorasi secara mendalam juga dilakukan terhadap dampaknya pada potensi risiko tidak tercapainya kualitas layanan dan keselamatan pasien. Meskipun demikian, keterbatasan penelitian yang harus digarisbawahi adalah bahwa transferability penelitian ini mungkin

(C) Poltekkes Kemenkes Jakarta I

Jl. Wijaya Kusuma No. 47-48 Cilandak Jakarta Selatan, Indonesia email: jurnalquality@poltekkesjakarta1.ac.id terbatas pada setting layanan primer dengan konteks yang serupa dengan Puskesmas yang diteliti. Selain itu, meskipun dilakukan eksplorasi lebih lanjut dengan wawancara mendalam, desain penelitian ini belum dapat menunjukkan kausalitas faktor-faktor dan dampak terkait keterbatasan waktu kontak.

\section{Kesimpulan dan Saran}

Rata-rata waktu kontak pasien dengan petugas kesehatan sangat singkat. Kurangnya jumlah petugas kesehatan dan beban administratif menjadi faktor yang menyebabkan keterbatasan waktu. Adanya budaya keselamatan pasien termasuk keterbukaan komunikasi yang terus dapat ditingkatkan menjadi faktor pemungkin perbaikan di masa mendatang. Terdapat perbedaan persepsi pasien terhadap kualitas layanan kesehatan terkait waktu tunggu serta harapan terpenuhinya preferensi mereka.

Kurangnya sumber daya manusia masih menjadi masalah krusial untuk memenuhi standar layanan di fasilitas kesehatan primer seperti Puskesmas. Hal ini perlu dipertimbangkan oleh pembuat kebijakan dalam memenuhi kebutuhan tenaga kerja di daerah. Di sisi yang lain, budaya keselamatan harus terus ditingkatkan salah satunya melalui proses akreditasi. Diperlukan manajemen staffing yang adekuat untuk memastikan beban kerja petugas kesehatan yang sesuai dan desain ulang alur layanan dalam di Puskesmas. Dibutuhkan komitmen level tinggi para pembuat kebijakan untuk memenuhi kebutuhan SDM di fasilitas kesehatan dan menerapkan sistem yang menjamin kualitas dan keselamatan pasien dalam layanan kesehatan.

Diperlukan penelitian lebih lanjut dengan jumlah sampel dan durasi observasi yang lebih lama untuk dapat lebih menggambarkan berbagai variasi layanan kesehatan primer di Indonesia. Selain itu, di samping menggali perspektif petugas kesehatan juga penting untuk digali perspektif pasien dan pemangku dalam penelitian yang akan datang guna memperkaya sudut pandang masalah dan pemecahannya. Dampak pandemi COVID-19 terhadap kecukupan waktu kontak pasien dengan petugas kesehatan, kualitas layanan, dan

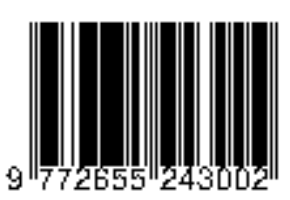


keselamatan pasien juga penting untuk untuk diteliti lebih lanjut.

\section{Daftar Pustaka}

Agrimon, O. H. (2014). Exploring the Feasibility of Implementing Self-Management and Patient Empowerment through a Structured Diabetes Education Programme in Yogyakarta City Indonesia: A Pilot Cluster Randomised Controlled Trial [The University of Adelaide]. In The University of Adelaide (Issue July). https://digital.library.adelaide.edu.au/dspace/b itstream/2440/87696/8/02whole.pdf

AHRQ. (2016). Surveys on Patient Safety Culture | Agency for Healthcare Research \& Quality. http://www.ahrq.gov/professionals/qualitypatient-safety/patientsafetyculture/index.html

Allen-Duck, A., Robinson, J. C., \& Stewart, M. W. (2017). Healthcare Quality: A Concept Analysis. Nurs Forum., 52(4), 377-386. https://doi.org/10.1111/nuf.12207.

Australian Commission on Safety and Quality in Healthcare. (2011). Patient safety in primary health care - Consultation Report (Issue July). https://www.safetyandquality.gov.au/wpcontent/uploads/2012/03/Primary-HealthCare-Consultation-Report-July-2011.pdf

Diab, S. M. (2015). The Effect of Primary Health Accreditation Standards on the Primary Health Care Quality and Employees Satisfaction in the Jordanian Health Care Centers. International Journal of Academic Research in Business and Social Sciences, 5(4), 204-220. https://doi.org/10.6007/IJARBSS/v5-i4/1568

El-Jardali, F., Hemadeh, R., Jaafar, M., Sagherian, L., El-Skaff, R., Mdeihly, R., Jamal, D., \& Ataya, N. (2014). The impact of accreditation of primary healthcare centers : Successes, challenges and policy implications as perceived ... The impact of accreditation of primary healthcare centers : successes, challenges and policy implications as perceived by healthca. BMC Health Services Research, 14(1), 1-10. https://doi.org/10.1186/1472-6963-14-86

Flott, K., Fontana, G., \& Darzi, A. (2019). The Global State of Patient Safety (Issue January). Imperial College London.

(C) Poltekkes Kemenkes Jakarta I

Jl. Wijaya Kusuma No. 47-48 Cilandak Jakarta Selatan, Indonesia email: jurnalquality@poltekkesjakarta1.ac.id https://www.imperial.ac.uk/media/imperialcollege/institute-of-global-healthinnovation/GlobalStateofPS_DIGITAL_16Se p19[2].pdf

Giles, S., Panagioti, M., Hernan, A., Cheraghi-Sohi, S., \& Lawton, R. (2015). Contributory factors to patient safety incidents in primary care: protocol for a systematic review. Systematic Reviews, 4(1), 63. https://doi.org/10.1186/s13643-015-0052-0

Haj-ali, W. (2012). PROMOTING EVIDENCEBASED PRIMARY HEALTHCARE ACCREDITATION POLICIES. Human \& Health, N2O(July), 34-36.

Halligan, M., \& Zecevic, A. (2011). Safety culture in healthcare: a review of concepts, dimensions, measures and progress. $B M J$ Quality \& Safety, 20(4), 338-343. https://doi.org/10.1136/bmjqs.2010.040964

Institute of Medicine (IOM). (2000). To Err Is Human (L. T. Kohn, J. M. Corrigan, \& S. Molla (eds.)). https://www.ncbi.nlm.nih.gov/books/NBK225 182/ doi: 10.17226/9728

Irving, G., Neves, A. L., Dambha-Miller, H., Oishi, A., Tagashira, H., Verho, A., \& Holden, J. (2017). International variations in primary care physician consultation time: A systematic review of 67 countries. BMJ Open, 7(10), 115. https://doi.org/10.1136/bmjopen-2017017902

Jafry, M. A., Jenny, A. M., Lubinga, S. J., LarsenCooper, E., Crawford, J., Matemba, C., \& Babigumira, J. B. (2016). Examination of patient flow in a rural health center in Malawi. BMC Research Notes, 9(1), 1-6. https://doi.org/10.1186/s13104-016-2144-x

Konrad, T. R., Link, C. L., Shackelton, R. J., Marceau, L. D., Knesbeck, O. von dem, Siegrist, J., Arber, S., Adams, A., \& McKinlay, J. B. (2010). Its about time: Physicians' perceptions of time constraints in primary care medical practive in three national healthcare systems. Med Care, 48(2), 95-100.

https://doi.org/10.1097/MLR.0b013e3181c12 e6a.It

Leppin, A., Montori, V., \& Gionfriddo, M. (2015). Minimally Disruptive Medicine: A

ISSN 2655-2434 
Pragmatically Comprehensive Model for Delivering Care to Patients with Multiple Chronic Conditions. Healthcare, 3(1), 50-63. https://doi.org/10.3390/healthcare3010050

Leslie, H. H., Laos, D., Cárcamo, C., \& PerezCuevas, R. (2021). Health care provider time in public primary care facilities in Lima, Peru: a cross-sectional time motion study. $B M C$ Health Service Research, 21(123), 1-11. https://doi.org/https://doi.org/10.1186/s12913021-06117-9

Lopetegui, M., Yen, P. Y., Lai, A., Jeffries, J., Embi, P., \& Payne, P. (2014). Time motion studies in healthcare: What are we talking about? In Journal of Biomedical Informatics (Vol. 49, pp. 292-299). Academic Press Inc. https://doi.org/10.1016/j.jbi.2014.02.017

Mahendradhata, Y., Trisnantoro, L., Listyadewi, S., Soewondo, P., Marthias, T., Harimurti, P., \& Prawira, J. (2017). The Republic of Indonesia Health System Review. Health System in Transition, 7(1), 1-293. https://apps.who.int/iris/handle/10665/254716

Marchon, SG; Junior, WVM; Pavão, A. (2015). Characteristics of adverse events in primary health care in Brazil Características dos eventos adversos na atenção primária à saúde no Brasil Características de los eventos adversos en la atención primaria de salud en Brasil. Cad. Saúde Pública, 31(11), 1-16. https://doi.org/http://dx.doi.org/10.1590/0102311X00194214

Marchon, SG; Junior, W. (2014). Patient safety in primary health care_a systematic review. Cad. Saúde Pública, 30(no.9).

https://doi.org/http://dx.doi.org/10.1590/0102311X00114113

Martinez, K. A., Dy, S. M., Weaver, S., Lubomski, L., Wilson, R., \& Pfoh, E. (2016). Promoting a culture of safety as a patient safety strategy : A systematic review. Ann Intern Med, 158, 369-374. https://doi.org/10.7326/0003-4819158-5-201303051-00002.Promoting

Mun, H. W., Kim, J. H., Ahn, J. H., Chang, I. B., Song, J. H., \& Oh, J. K. (2019). Patient's preference on neurosurgeon's attire and appearance: A single center study in korea cross-sectional study. BioMed Research International, 2019, 6-11.

(C) Poltekkes Kemenkes Jakarta I

J1. Wijaya Kusuma No. 47-48 Cilandak Jakarta Selatan, Indonesia email: jurnalquality@ poltekkesjakarta1.ac.id https://doi.org/10.1155/2019/3893049

Newell, S., \& Jordan, Z. (2015). The patient experience of patient-centered communication with nurses in the hospital setting: a qualitative systematic review protocol. JBI Database of Systematic Reviews and Implementation Reports, 13(1), 76-87. https://doi.org/10.11124/jbisrir-2015-1072

O’Beirne, M; Zwicker, K; Sterling, PD; Lait, J; Robertson, HL; Oelke, N. (2013). The status of accreditation in primary care. 23-31.

Paternotte, E., van Dulmen, S., Bank, L., Seeleman, C., Scherpbier, A., \& Scheele, F. (2017). Intercultural communication through the eyes of patients: experiences and preferences. International Journal of Medical Education, $8,170-175$. https://doi.org/10.5116/ijme.591b.19f9

Pérez-Francisco, D. H., Duarte-Clíments, G., Del Rosario-Melián, J. M., Gómez-Salgado, J., Romero-Martín, M., \& Sánchez-Gómez, M. B. (2020). Influence of workload on primary care nurses' health and burnout, patients' safety, and quality of care: Integrative review. Healthcare (Switzerland), 8(1), 1-14. https://doi.org/10.3390/healthcare8010012

Petrilli, C. M., Mack, M., Petrilli, J. J., Hickner, A., Saint, S., \& Chopra, V. (2015). Understanding the role of physician attire on patient perceptions: A systematic review of the literature - Targeting attire to improve likelihood of rapport (TAILOR) investigators. BMJ Open, 5(1). https://doi.org/10.1136/bmjopen-2014-006578

Sheikh, A., Panesar, S. S., Larizgoitia, I., Bates, D. W., \& Donaldson, L. J. (2013). Safer primary care for all: A global imperative. The Lancet Global Health, 1(4), e182-e183. https://doi.org/10.1016/S2214109X(13)70030-5

Singh, H., Schiff, G. D., Graber, M. L., Onakpoya, I., \& Thompson, M. J. (2017). The global burden of diagnostic errors in primary care. BMJ Quality \& Safety, 26(6), 484-494. https://doi.org/10.1136/bmjqs-2016-005401

Smith, K. M., Baker, K., Wesley, D., Zipperer, L., Clark, M. D., Hanneke, R., Stoto, M. A., \& Goeschel, C. A. (2017). Guide to Improving Patient Safety in Primary Care Settings by

ISSN 2655-2434 
Engaging Patients and Families (Issue 17). http://www.ahrq.gov/professionals/qualitypatient-safety/patient-familyengagement/pfeprimarycare/index.html Sterling, P., Lait, J., Lewanczuk, R., Ghali, W., \& Robertson, H. L. (2012). A Synthesis of Quality Improvement and Accreditation Mechanisms in Primary Healthcare (Issue December).

Tsiga, E., Panagopoulou, E., Sevdalis, N., \& Montgomery, A. (2013). The influence of time pressure on adherence to guidelines in primary care : an experimental study. $B M J$ Open, 3(e002700), 1-6. https://doi.org/10.1136/bmjopen-2013-002700

Von Dem Knesebeck, O., Koens, S., Marx, G., \& Scherer, M. (2019). Perceptions of time constraints among primary care physicians in Germany. BMC Family Practice, 20(1), 7-11. https://doi.org/10.1186/s12875-019-1033-5

Wong, K., Boulanger, L., Smalarz, A., Wu, N., Fraser, K., \& Wogen, J. (2013). Impact of care management processes and integration of care on blood pressure control in diabetes. BMC Family Practice, 14(30), 1-10.

World Health Organisation. (2008). WHO patient safety curriculum guide for medical schools. Quality \& Safety in Health Care, 19(6), 542546.

https://doi.org/10.1136/qshc.2009.036970 